\title{
BMJ Open Determinants of health insurance ownership in Jordan: a cross-sectional study of population and family health survey 2017-2018
}

\author{
Meilian Liu (D) , ${ }^{1}$ Zhaoxin Luo, ${ }^{1}$ Donghua Zhou, ${ }^{2}$ Lu Ji, ${ }^{3}$ Huilin Zhang, ${ }^{3}$ \\ Bishwajit Ghose (i) , ${ }^{4}$ Shangfeng Tang, ${ }^{3}$ Ruoxi Wang (i) , ${ }^{3}$ Da Feng (i) ${ }^{5}$
}

To cite: Liu M, Luo Z, Zhou D, et al. Determinants of health insurance ownership in Jordan: a cross-sectional study of population and family health survey 2017-2018. BMJ Open 2021;11:e038945. doi:10.1136/ bmjopen-2020-038945

- Prepublication history for this paper is available online To view these files, please visit the journal online (http://dx.doi. org/10.1136/bmjopen-2020038945).

Received 02 April 2020 Revised 22 December 2020 Accepted 30 December 2020

Check for updates

(c) Author(s) (or their employer(s)) 2021. Re-use permitted under CC BY-NC. No commercial re-use. See rights and permissions. Published by BMJ.

${ }^{1}$ School of Business, Guilin University of Electronic Technology, Guilin, China ${ }^{2}$ School of Physical Education, Research Center of Sports and Health, Wuhan Business University, Wuhan, China ${ }^{3}$ School of Medicine and Health Management, Tongji Medical College, Huazhong University of Science and Technology, Wuhan, China

${ }^{4}$ Social Sciences and Humanities Research Council of Canada, University of Ottawa, Ottawa, Ontario, Canada

${ }^{5}$ School of Pharmacy, Huazhong University of Science and Technology, Wuhan, China

Correspondence to Da Feng; fengda@hust.edu.cn

\section{ABSTRACT}

Objectives With about one-third of the population living below the poverty line, Jordan faces major healthcare, social and national development issues. Low insurance coverage among the poor and high out-of-pocket expenditure worsens the financial insecurity especially for the marginalised population. The Government of Jordan aims to achieve universal coverage of health insurance-a bold plan that requires research evidence for successful implementation. In this study, we aimed to assess the proportion of the population covered by any health insurance, and the determinants owing a health insurance. Design A population-based prospective cohort study. Setting Jordan.

Methods Data for this study were derived from the Jordan Population and Family Health Survey, which was implemented by the Department of Statistics from early October 2017 to January 2018. Sample characteristics were described as percentages with $95 \% \mathrm{Cls}$. Binary logistic regression models were used to estimate $\mathrm{OR}$ of health insurance ownership. Parsimonious model was employed to assess the sex and geographical differences. Results Data revealed that in 2017-2018, 73.13\% of the 12992 men and women had health insurance. There was no indication of age of sex difference in health insurance ownership; however, marital status and socioeconomic factors such as wealth and education as well as internet access and geographical location appeared to be the important predictors of non-use of health insurance. The associations differed by sex and urbanicity for certain variables. Addressing these inequities may help achieve universal coverage in health insurance ownership in the population.

Conclusions More than one-quarter of the population in Jordan were not insured. Efforts to decrease disparities in insurance coverage should focus on minimising socioeconomic and geographical disparities to promote equity in terms of healthcare services.

\section{BACKGROUND}

Jordan is an upper middle-income country in the middle-eastern region and has been experiencing rising life expectancy and improving living standards during last twothree decades. Between 1990 and 2015, the
Strengths and limitations of this study

- This study of Jordan Population and Family Health Survey (2017-2018) which is nationally representative and cross-sectional in nature.

- We had comprehensive information on potential confounding factors.

- Selection bias cannot completely be excluded as $42.35 \%$ were people younger than 20 years old.

average life expectancy rose from 69.9 to 74.1 years. ${ }^{1}$ The country boasts a high-quality healthcare system and is considered one of the major destinations for medical tourism in the Middle East and North Africa (MENA) region. ${ }^{1}$ In terms of medical tourism, World Bank ranks Jordan as the leader in the MENA region and fifth in the world, with the sector generating a revenue of over $\$ 1.5$ billion per year. ${ }^{2}$ Irrespective of the relatively better socioeconomic situation than many countries in Asia, poverty and health inequality are not uncommon and are recognised as important challenges to health promotion in the country. In fact, inequal access to care is seen in all countries and is regarded as a core development challenge for the low-middle countries. Healthcare services in Jordan are provided through the public/semi-public and the private sector, and consists of 106 hospitals in total. There is home-based healthcare service that is provided mainly by the private sector which is not covered by health insurance, and therefore remains beyond the affordability of most patients. ${ }^{1}$ Direct outof-pocket (OUP) health expenditure makes up about one-quarter of total healthcare spending, which is considerably high for a middle-income country. ${ }^{1}$

Global health institutions and national governments are striving to address inequality at all aspects of public health through policies 
such as universal healthcare coverage (UHC) as a part of the sustainable goals (SDGs). ${ }^{3}{ }^{4}$ UHC is defined as: everyone receiving quality health services that meet their needs without exposing them to financial hardship in paying for them..$^{5}$ Achieving UHC is a daunting task due to numerous financial, structural and political barriers, and hence remains an elusive goal particularly in the developing countries. While there is no clear consensus on how UHC can be achieved, experts suggest the financial burden of accessing healthcare for the poor can be mitigated by ensuring removal of user fees through instruments such as strategic insurance schemes. ${ }^{6-9}$ Improving health insurance coverage has become a major strategy to improving financial risk protection and access to quality healthcare..$^{1011}$

Increasing the usage of health insurance in countries with high poverty rates and entrenched inequality is important for several critical reasons. First, people who are unable to afford the cost of care and uninsured are less likely to access the services, and consequently experience poorer health outcomes and are more likely to fall into extreme poverty. In unavoidable circumstances, individuals are forced to spend on healthcare by cutting expenses from other basic needs, which in turn can have potential adverse effects on the health of the family. Jordan has a national health insurance policy and according to some estimates, more than half of the population are insured. ${ }^{1}$ Reaching the uninsured population is a complex task especially when they are living or working in informal settings (eg, refugee camps), which systematically excludes them form formal intervention programmes. ${ }^{12} 13$ This type of exclusion from the benefits of healthcare system, or loss of medical citizenship can be hard to remedy, and will require identification of the communities who are deprived economically and sociodemographically and geographically. ${ }^{14-17}$

In Jordan, the most commonly encountered health conditions are non-communicable diseases (NCDs), ${ }^{18}$ which require life-long care and dependency on medical expenditures. Individuals living with NCDs are thus more vulnerable to catastrophic healthcare spending unless supported by health insurance programmes. Given the increasing burden of NCDs in the country, there is an urgent need to reinforce efforts for promoting UHC and health insurance to safeguard the vulnerable population. In this context, understanding the existing inequalities in the distribution of health insurance users can be a key step to action. Previous studies has demonstrated the role of economic, ${ }^{19}$ geographic, ${ }^{20}$ racial and ethnic ${ }^{21}$ variation in health insurance coverage; however, no such evidence is currently available for Jordan. To this regard, this study was conducted with the aim of assessing the proportion of population possessing any type of health insurance and whether or not there is any significant variation in insurance ownership across the sociodemographic groups. We used data from Jordan Population and Family Health Survey (2017-2018) which is nationally representative and cross-sectional in nature. The study was based on the hypothesis that health insurance ownership will differ significantly by socioeconomic status.

\section{METHODS \\ Study population}

Survey and data collection

The 2017-2018 Jordan Population and Family Health Survey (JPFHS) was the seventh of this kind to be conducted in the country, and was implemented by the Department of Statistics (DOS) from early October 2017 to January 2018. The funding for the JPFHS was provided by the government of Jordan, the U.S. Agency for International Development (USAID), the United Nations Children's Fund (UNICEF) and the United Nations Population Fund (UNFPA). Technical assistance for the survey was provided by ICF international through The Demographic and Health Survey (DHS) Programme, a USAID-funded project that provides support and technical assistance in the implementation of population health surveys in about 90 low-middle income countries.

The main objectives of the survey were to collect data on key demographical indicators such as fertility, childhood mortality, maternal and child health status. Data serve the purpose of measuring the progress towards national and international development goals (such as sustainable development goals) and facilitating evidence-based policies. The latest JPFHS survey was nationally representative. It collected data from urban and rural areas separately across all 12 administrative regions. The survey employed a two-stage sampling technique. In the first stage, 970 clusters were selected with probability proportional to cluster size, and in the second stage 20 households per cluster were selected for interview. In total, 19383 households were selected of which 18802 finally interviewed (response rate 98.3\%). For further reading: Department of Statistics (DOS) and ICF. 2019. Jordan Population and Family and Health Survey 2017-2018. Amman, Jordan and Rockville, Maryland, USA: DOS and ICF.

\section{Main variables}

The outcome variable was insurance ownership. This was measured by asking the main respondent about the insurance ownership of household members. Answer to this question was categorised as 'Covered by health insurance' and 'Not covered'. Several enabling and predisposing factors were chosen as the predictor variables based on their theoretical association with insurance ownership: age in years $(<20,20 / 29,30 / 39,40 / 49$, $50 / 59,>60$ ), sex (male, female), marital status (never married, married, widowed), residency (urban, rural), region (Amman, Balqa, Zarqua, Madaba, Irbid, Mafraq, Jerash, Aljoun, Karak, Tafilh, Maan, Aquaba), education (no education/preschool, primary, secondary, higher), wealth quintile (poorest, poorer, middle, richer, richest), access to internet (yes, no), access to mobile phone (yes, no). ${ }^{11} 1922-24$ 
As explained in previous studies, wealth status is calculated by a score assigned to households based on the possession of durable goods (eg, TV, radio, refrigerator and construction material). Categorisation was performed by dividing the household wealth scores into quintiles. The richest households were those in the highest quintile, and poorest were in the lowest quintile. ${ }^{25}$

\section{Statistical analysis}

Data were analysed with Stata V.14. All analyses were adjusted for the cluster design by using the suy command. ${ }^{26}$ This command uses the information on sampling weight, strata and primary sampling unit provided with the datasets. Sample characteristics were described as percentages with $95 \%$ CIs. Following that, binary logistic regression models were used to estimate odds ratio (with 95\% CIs) of health insurance ownership. At first, we ran a full-model analysis including all the explanatory variables, followed by a parsimonious model that excluded variables showing no significant bivariate association $\left(X^{2} p>0.05\right)$ with the outcome. Previous studies have reported that health insurance ownership can vary by sex and residency. Therefore, we further extended the parsimonious model to assess for sex and geographic differences. Variance inflation factor (VIF) command was used to test for multi-collinearity. No multi-collinearity was detected as VIF values were below 10 for all the models. All tests were two-tailed and were considered significant at alpha value of $5 \%$.

\section{Patient and public involvement}

No patient was involved in this study. The data were secondary and were downloaded from DHS website for this research.

\section{RESULTS}

Sample population consisted of 12992 men $(n=6446)$ and women $(n=6546)$ living in urban $(n=10683)$ and rural areas $(n=2309)$. As shown in table $1,73.13 \%$ (95\% CI $=60.59$ to 66.77$)$ of the participants were covered by health insurance. The percentage of insurance ownership varied significantly $(\mathrm{p}<0.001)$ across several sociodemographical factors including marital status, residency, region, educational level and having access to internet.

Table 2 shows the ORs of health insurance ownership for the full and parsimonious models. In the full model, the odds of health insurance ownership were found to be increasing gradually with higher age groups, with the ORs being highest among those in the age groups of $>60$ years $(\mathrm{OR}=1.773,95 \% \mathrm{CI}=1.353$ to 2.324$)$. The odds of health insurance ownership were lower among those who never married or widowed compared with those were currently married. The odds or comparatively higher in the urban areas in both of the models. Apart from urbanicity, significant regional differences were observed in health insurance ownership. Regarding education, those who completed primary had comparatively lower, and those who completed higher education had comparatively higher odds of health insurance ownership. In the full model, wealth status showed a positive association with health insurance ownership, with the odds being higher among those living in the non-poor households (middle, richest). Having access to mobile phone $(\mathrm{OR}=1.802,95 \%$ $\mathrm{I}=1.383$ to 2.347$)$ and internet $(\mathrm{OR}=2.381,95 \% \mathrm{CI}=1.432$ to 3.950 ) also showed significant association with health insurance ownership.

We further subdivided the parsimonious model to assess for sex (table 3) and geographic differences (table 4). Table 3 shows that being widowed was associated with lower odds of health insurance ownership among women $(\mathrm{OR}=0.740,95 \% \mathrm{CI}=0.568$ to 0.964$)$ but not among men, whereas urban residency increased the odds among both sexes. Regional differences in health insurance ownership were generally similar for both sexes. Regarding education, the negative association for primary level completion and positive association for higher level completion were slightly stronger among men. The association between internet access and health insurance ownership was not statistically significant after stratifying by sex.

Table 4 indicates that being widowed was associated with lower odds of health insurance ownership in the urban areas only $(\mathrm{OR}=0.718,95 \% \mathrm{CI}=0.564$ to 0.914$)$. Regional patterns in health insurance ownership were generally similar between urban and rural areas. With respect to educational status, the negative association between primary completion and health insurance ownership was significant in urban areas; whereas for higher education, the positive association was observed in both urban and rural areas. However, the effect was comparatively higher in the rural areas (OR 1.324 in the urban vs 3.390 in the rural areas).

\section{DISCUSSION}

The present study aimed to assess the prevalence and predictors of health insurance ownership among the mainstream population in Jordan. Data were taken from Jordan Population and Family Health Survey, and the findings suggest that little less than three-quarter of the population had any health insurance. This finding is similar to a report published in 2016, that highlighted that $68 \%$ of Jordanians and $55 \%$ of the overall population are covered by some type of health insurance. ${ }^{27}$ This is indicative of the fact that the proportion of insurance coverage is considerably lower among non-native population. It is also important to note that Jordanian children under 6 years of age are entitled by a Royal decree to free healthcare services, and therefore including the under-six population in the statistics may not represent the accurate picture of voluntary health insurance coverage in the entire population.

Our analysis indicated significant sociodemographic disparities in the prevalence of health insurance ownership. These factors included age, marital status, residency, region, educational status and access to internet. Although the under-six population are automatically 
Table 1 Distribution of sample population by insurance ownership status $(n=12992)$

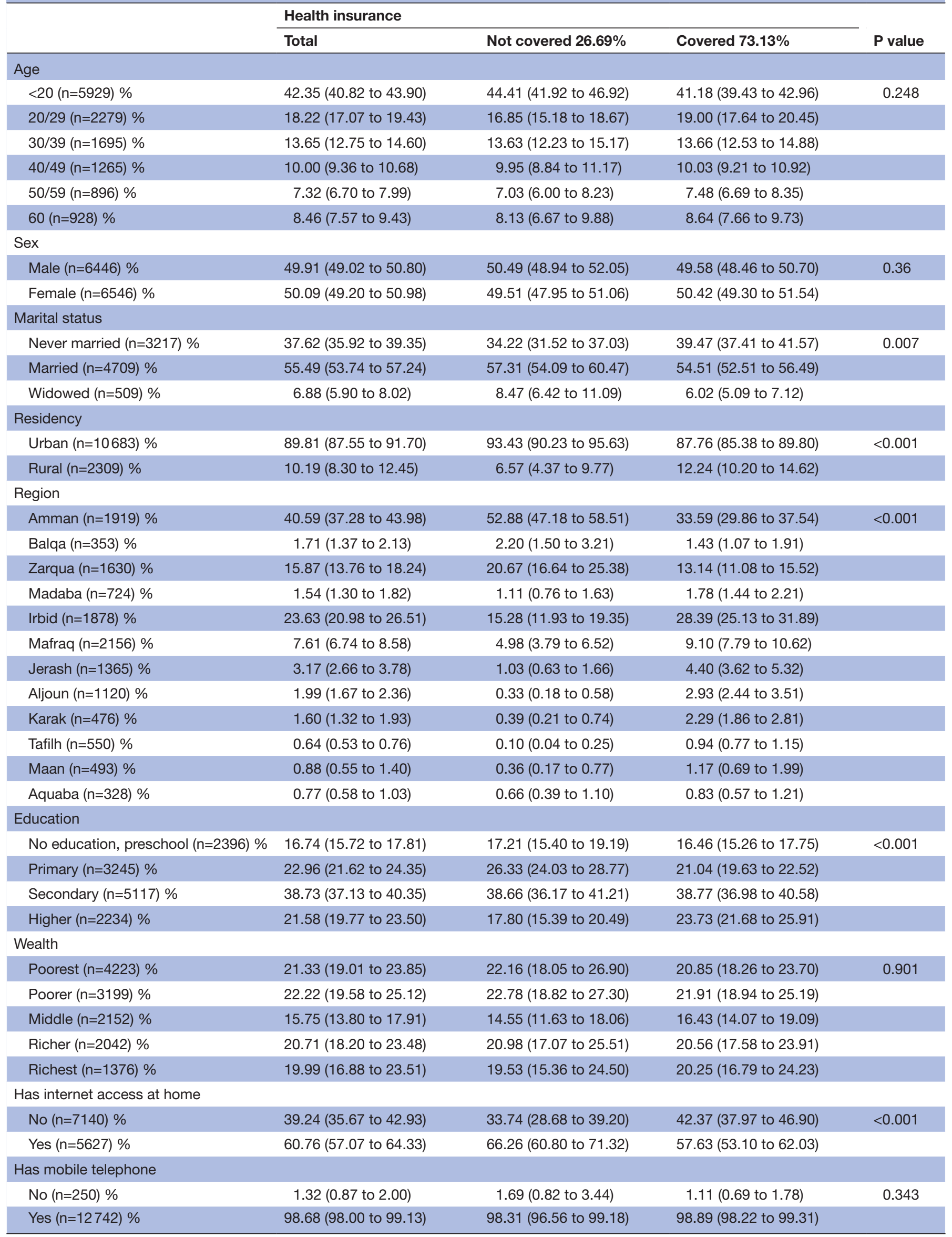


Table 2 Factors associated with of health insurance ownership

\begin{tabular}{|c|c|c|}
\hline & Full model & Parsimonious model \\
\hline Age (<20 years) & 1 & \\
\hline $20 / 29$ & $1.156(0.970$ to 1.378$)$ & \\
\hline $30 / 39$ & $1.280^{*}(1.036$ to 1.580$)$ & \\
\hline $40 / 49$ & $1.388^{\star \star}(1.105$ to 1.745$)$ & \\
\hline $50 / 59$ & $1.456^{\star \star}(1.133$ to 1.871$)$ & \\
\hline$>60$ & $1.773^{* \star *}$ (1.353 to 2.324$)$ & \\
\hline Sex (male) & 1 & \\
\hline Female & 0.972 (0.873 to 1.084$)$ & \\
\hline $\begin{array}{l}\text { Marital status } \\
\text { (married) }\end{array}$ & 1 & 1 \\
\hline Never married & $0.797^{\star \star}(0.682$ to 0.931$)$ & $0.791^{* \star}$ (0.678 to 0.922$)$ \\
\hline Widowed & $0.602^{* \star *}(0.462$ to 0.786$)$ & 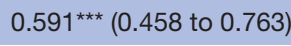 \\
\hline Residency (rural) & 1 & 1 \\
\hline Urban & $1.430^{* \star *}(1.203$ to 1.700$)$ & 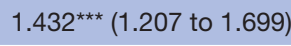 \\
\hline Region (Amman) & 1 & 1 \\
\hline Balqa & 1.237 (0.925 to 1.655$)$ & $1.303(0.979$ to 1.735$)$ \\
\hline Zarqua & $1.246^{*}(1.050$ to 1.479$)$ & $1.231^{*}$ (1.039 to 1.460$)$ \\
\hline Madaba & $2.296^{\star \star \star}$ (1.810 to 2.911$)$ & $2.324^{\star \star \star}(1.837$ to 2.941$)$ \\
\hline Irbid & $2.875^{\star \star \star}$ (2.399 to 3.445$)$ & $2.868^{\star \star \star}(2.405$ to 3.420$)$ \\
\hline Mafraq & $3.997^{* * *}(3.250$ to 4.916$)$ & $3.983^{\star \star *}$ (3.276 to 4.843$)$ \\
\hline Jerash & $5.245^{\star \star \star}$ (4.116 to 6.685$)$ & $5.117^{\star \star \star}(4.080$ to 6.418$)$ \\
\hline Aljoun & $14.31^{\star \star \star}(10.15$ to 20.17$)$ & $14.23^{\star \star \star}(10.22$ to 19.81$)$ \\
\hline Karak & $6.469^{\star \star \star}(4.452$ to 9.400$)$ & $6.630^{\star \star \star}(4.566$ to 9.628$)$ \\
\hline Tafilh & $20.53^{\star \star \star}(11.90$ to 35.41$)$ & $17.26^{\star \star \star}(10.40$ to 28.64$)$ \\
\hline Maan & $6.291^{* * *}$ (4.422 to 8.949$)$ & $5.988^{* * *}(4.253$ to 8.431$)$ \\
\hline Aquaba & $1.923^{\star * \star}$ (1.386 to 2.668$)$ & $1.868^{\star \star \star}(1.358$ to 2.568$)$ \\
\hline $\begin{array}{l}\text { Education (no } \\
\text { education, } \\
\text { preschool) }\end{array}$ & 1 & 1 \\
\hline Primary & $0.755^{\star}(0.585$ to 0.975$)$ & $0.762^{*}(0.594$ to 0.978$)$ \\
\hline Secondary & 1.104 (0.870 to 1.400$)$ & 1.127 (0.895 to 1.419$)$ \\
\hline Higher & $1.612^{\star \star \star}$ (1.243 to 2.089$)$ & $1.624^{\star \star \star}(1.259$ to 2.093$)$ \\
\hline $\begin{array}{l}\text { Wealth quintile } \\
\text { (poorest) }\end{array}$ & 1 & \\
\hline Poorer & 1.099 (0.942 to 1.281$)$ & \\
\hline Middle & $1.553^{\star \star \star}(1.302$ to 1.853$)$ & \\
\hline Richer & 1.165 (0.980 to 1.385$)$ & \\
\hline Richest & $1.411^{\star \star}(1.145$ to 1.737$)$ & \\
\hline $\begin{array}{l}\text { Internet access } \\
\text { (no) }\end{array}$ & 1 & 1 \\
\hline Yes & $1.802^{* \star *}(1.383$ to 2.347$)$ & $3.304^{\star \star}(1.371$ to 7.973$)$ \\
\hline $\begin{array}{l}\text { Mobile phone } \\
\text { access (no) }\end{array}$ & 1 & \\
\hline Yes & $2.381^{\star \star \star}(1.432$ to 3.950$)$ & \\
\hline
\end{tabular}

Exponentiated coefficients; 95\% Cls in brackets.

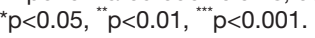

covered by free healthcare services, the likelihood of insurance ownership was relatively lower in the age group of $<20$ years, indicating that the insurance coverage among the adolescent population can be comparatively
Table 3 Sex differences in the factors associated with of health insurance ownership in Jordan

\begin{tabular}{|c|c|c|}
\hline & Men & Women \\
\hline $\begin{array}{l}\text { Marital status } \\
\text { (married) }\end{array}$ & 1 & 1 \\
\hline Never married & 0.959 (0.820 to 1.122$)$ & 0.962 (0.817 to 1.132$)$ \\
\hline Widowed & 1.031 (0.563 to 1.890$)$ & $0.740^{\star^{*}}(0.568$ to 0.964$)$ \\
\hline $\begin{array}{l}\text { Residence } \\
\text { (rural) }\end{array}$ & 1 & 1 \\
\hline Urban & $1.423^{\star *}(1.117$ to 1.813$)$ & $1.496^{\star \star \star}(1.187$ to 1.884$)$ \\
\hline Region (Amman) & 1 & 1 \\
\hline Balqa & 1.036 (0.684 to 1.571$)$ & 1.365 (0.914 to 2.038 ) \\
\hline Zarqua & 1.104 (0.868 to 1.404$)$ & $1.290^{*}(1.023$ to 1.626$)$ \\
\hline Madaba & $1.984^{\star \star \star}(1.422$ to 2.768$)$ & $2.379^{\star \star \star}(1.714$ to 3.302$)$ \\
\hline Irbid & $2.280^{\star \star \star}(1.782$ to 2.915$)$ & $3.043^{\star \star \star}(2.384$ to 3.885$)$ \\
\hline Mafraq & $3.574^{\star \star \star}(2.711$ to 4.710$)$ & $3.032^{\star \star \star}(2.354$ to 3.905$)$ \\
\hline Jerash & $4.616^{\star \star \star}$ (3.318 to 6.423$)$ & $4.663^{\star \star \star}(3.393$ to 6.409$)$ \\
\hline Aljoun & $15.00^{\star \star \star}$ (8.970 to 25.07$)$ & $11.24^{\star \star \star}(7.251$ to 17.41$)$ \\
\hline Karak & $6.731^{\star \star \star}(3.886$ to 11.66$)$ & $5.735^{\star \star \star}(3.466$ to 9.490$)$ \\
\hline Tafilh & $15.33^{\star \star \star}(7.351$ to 31.98$)$ & $20.48^{\star \star \star}(9.427$ to 44.50$)$ \\
\hline Maan & $6.310^{\star \star \star}$ (3.727 to 10.69$)$ & $5.251^{\star \star \star}(3.312$ to 8.326$)$ \\
\hline Aquaba & $1.796^{\star}(1.145$ to 2.816$)$ & $1.795^{\star}(1.130$ to 2.852$)$ \\
\hline $\begin{array}{l}\text { Education } \\
\text { (none) }\end{array}$ & 1 & 1 \\
\hline Primary & $0.615^{\star}(0.398$ to 0.952$)$ & $0.715^{\star}(0.524$ to 0.975$)$ \\
\hline Secondary & 0.976 (0.653 to 1.459$)$ & 0.927 (0.715 to 1.202$)$ \\
\hline Higher & $1.630^{*}(1.065$ to 2.496$)$ & $1.401^{*}(1.052$ to 1.865$)$ \\
\hline $\begin{array}{l}\text { Internet access } \\
\text { (no) }\end{array}$ & 1 & 1 \\
\hline Yes & 1.012 (0.853 to 1.201$)$ & 1.036 (0.880 to 1.219$)$ \\
\hline
\end{tabular}

Exponentiated coefficients; 95\% Cls in brackets. ${ }^{*} p<0.05, " \mathrm{p}<0.01, " \mathrm{p} p<0.001$.

lower than other age groups. Interestingly, marital status showed a significant association with health insurance ownership. ${ }^{22}{ }^{28}$ People who were currently married were more likely to report having insurance than those who never married/widowed. This might be due the age structure and level of financial solvency among married people. People who are too young, and elderly, may not be as self-efficient about health status as those who fall in between. ${ }^{29}{ }^{30}$ Significant differences in insurance ownership were also observed by region and urbanicity with urban population showing relatively higher likelihood of the health insurance ownership. The urbanrural disparity in insurance ownership, as well as overall healthcare service utilisation has been documented in prior studies, highlighting a growing trend in geographic inequality in healthcare. ${ }^{24} 3132$

Educational status also showed significant association with health insurance ownership, such as that those who completed primary had comparatively lower, and those who completed higher education had comparatively higher odds of health insurance ownership. The negative association for primary level education is a surprising 


\begin{tabular}{|c|c|c|}
\hline & Urban & Rural \\
\hline $\begin{array}{l}\text { Marital status } \\
\text { (married) }\end{array}$ & 1 & 1 \\
\hline $\begin{array}{l}\text { Never } \\
\text { married }\end{array}$ & 0.940 (0.834 to 1.059$)$ & 1.150 (0.813 to 1.626$)$ \\
\hline Widowed & $0.718^{\star \star}(0.564$ to 0.914$)$ & 1.431 (0.671 to 3.052$)$ \\
\hline $\begin{array}{l}\text { Region } \\
\text { (Amman) }\end{array}$ & 1 & 1 \\
\hline Balqa & $1.157(0.861$ to 1.553$)$ & 1.576 (0.410 to 6.059$)$ \\
\hline Zarqua & $1.121(0.946$ to 1.328$)$ & $1.431^{*}(1.039$ to 1.860$)$ \\
\hline Madaba & $2.123^{\star * \star}$ (1.647 to 2.736$)$ & $3.216^{\star \star *}$ (1.709 to 6.052$)$ \\
\hline Irbid & $2.475^{\star \star \star}(2.068$ to 2.963$)$ & $7.117^{\star \star \star}(3.619$ to 14.00$)$ \\
\hline Mafraq & $3.229^{\star \star \star}(2.630$ to 3.963$)$ & $5.991^{* \star *}(3.504$ to 10.24$)$ \\
\hline Jerash & $3.569^{\star \star \star}(2.823$ to 4.513$)$ & $1.104(0.870$ to 1.400$)$ \\
\hline Aljoun & $10.35^{\star \star \star}(7.348$ to 14.59$)$ & $109.9^{\star \star \star}(24.83$ to 486.3$)$ \\
\hline Karak & $5.837^{\star \star \star}$ (3.634 to 9.377$)$ & $10.38^{\star \star \star}$ (5.279 to 20.42$)$ \\
\hline Tafilh & $12.70^{\star \star \star}(7.407$ to 21.76$)$ & 0.927 (0.715 to 1.202$)$ \\
\hline Maan & $7.616^{\star \star \star}(4.655$ to 12.46$)$ & $8.356^{\star \star \star}(4.477$ to 15.60$)$ \\
\hline Aquaba & $1.833^{\star * \star}(1.289$ to 2.607$)$ & $2.576^{*}(1.106$ to 5.997$)$ \\
\hline $\begin{array}{l}\text { Education } \\
\text { (none) }\end{array}$ & 1 & 1 \\
\hline
\end{tabular}

\begin{tabular}{|c|c|c|}
\hline Primary & $0.641^{\star \star}(0.489$ to 0.840$)$ & $0.760(0.408$ to 1.416$)$ \\
\hline Secondary & $0.876(0.690$ to 1.112$)$ & $1.646(0.967$ to 2.804$)$ \\
\hline Higher & $1.324^{*}(1.024$ to 1.712$)$ & $3.390^{* * \star}(1.784$ to 6.440$)$ \\
\hline $\begin{array}{l}\text { Internet access } \\
\text { (no) }\end{array}$ & 1 & 1 \\
\hline
\end{tabular}

Yes $\quad 1.075(0.949$ to 1.219$) \quad 0.621^{*}(0.425$ to 0.907$)$

Exponentiated coefficients; 95\% Cls in brackets.

${ }^{*} p<0.05,{ }^{* *} p<0.01,{ }^{* * *} p<0.001$.

one, and needs further investigation. In general, higher educational status is regarded as a key determinant of health literacy and self-efficacy, which in turn can result in better adherence to health promoting behaviour and activities for example, subscribing for health insurance. ${ }^{33}$ In addition, education in general is also positively correlated with better financial standing, which thereby allows individuals to be more health conscious and investing more resources to preventive measures. As such, individuals and families with better socioeconomic standing are more capable of affording health-promoting services, to which insurance ownership is a prominent example. Therefore, it is advisable that policy makers pay greater attention to the socioeconomically vulnerable population in order to promote health insurance ownership and universal health coverage.

Participants wealth status also showed a positive association with health insurance ownership as the odds were generally higher among those living in the nonpoor households. This finding emphasises the need for paying special attention to individuals with financial constraints that can pose barrier to accessing healthcare, and can have repercussions on health and socioeconomic mobility. ${ }^{34}$ As expected, having access to mobile phone and internet also showed significant association with health insurance ownership. Given the increasing population and demand for insurance and inadequate institutional facility, the ministry of health encourages applying for insurance through their online portal. ${ }^{35}$ Thus, people with access to these technologies are more likely to be able to apply for insurance compared with those deprived of these facilities. In countries with persistent healthcare disparities, mobile phone and internet-based innovations are gaining popularity due to their capacity for bridging the healthcare gaps. ${ }^{36-39}$ Focusing on these technologies may also prove beneficial for promoting health insurance in Jordan.

OUP health expenditure is a key driver of poverty especially among the marginalised population. Families living on a constrained budget may find it hard to afford a paid insurance scheme, and thus share a heightened risk of having to pay for medical care. In Jordan, OUP spending constitute about a quarter of the total healthcare spending. ${ }^{40}$ Increasing the coverage and ownership of health insurance is therefore an important strategy to safeguard the vulnerable population from the consequences of unexpected health expenditure. Although Jordan has the reputation of having one of the best healthcare systems in the region, the situation appears to be far more challenging than it seems given the large influx of refugees from certain neighbouring countries. ${ }^{41}$ As the population continues to increase, with the marginalised population comprising a comparatively larger segment, the prevalence of people with unmet need for healthcare is expected to rise significantly.

With the demographical shift occurring against the backdrop of decreasing national budget for healthcare, ${ }^{42}$ the importance of promoting healthcare insurance in Jordan cannot be overrated. Insurance ownership can be influenced by various geographic, socioeconomic and cultural factors, having a good understanding of which can help develop sound policies for addressing the inequalities. The present study was conducted based on secondary data, which means that the methodological design was dependent on the variables available for analysis. While this can be seen an important limitation, the findings nonetheless provide interesting insights regarding the existing inequalities in healthcare ownership in the country. Recent publications have highlighted the challenges associated with accessing healthcare among refugee population Jordan, ${ }^{43-46}$ however, this was not possible to assess in this study since this was not the focus of the survey. Further studies should be conducted by including the minority groups (eg, refugees) and assessing the healthcare related drivers of health insurance ownership in Jordan.

This study has several strengths and limitations to report. First, the sample population was relatively large and data were nationally representative. The strength of the survey was that the results have good external validity. 
Despite the data limitations, the analysis was carried out in a way to provide a clearer picture of the disparities across the subpopulation for example, sex and residency. Existing evidence supports the fact that men and women differ significantly in terms of using healthcare services, so the current findings regarding the sex difference in health insurance ownership is an important contribution to the literature. There are several limitations to report as well. First, the data were cross-sectional, and therefore we cannot confirm any directionality or causality of the associations. As reported earlier, the data were secondary and therefore the selection of study variable was a major constraint. Insurance coverage can be determined to a large extent by the supply side factors, but there were no data covering such topics. Last but not least, the data were self-reported and remain to subject to reporting bias.

\section{CONCLUSION}

We found that findings suggest that little more than onequarter of the sample population did not have any health insurance. Several sociodemographic factors, including marital status, household wealth, educational level, access to internet and geographic location were significantly associated with non-ownership of health insurance. The study concludes that efforts to decrease disparities in insurance coverage should focus on minimising socioeconomic and geographic disparities.

\section{Twitter Da Feng @fengda}

Acknowledgements The study is a collaboration between the Huazhong University of Science and Technology, Research Center of Sports and Health of School of Physical Education and School of Business, Guilin University of Electronic Technology.

Contributors ML, ZL and DF contributed to the study design and conducted statistical analysis and wrote the initial draft. DZ, LJ, ST and HZ contributed to the interpretation of results. RW, BG and DF critically revised the manuscript for important intellectual content. All authors approved the final version of manuscript.

Funding The authors have not declared a specific grant for this research from any funding agency in the public, commercial or not-for-profit sectors.

Competing interests None declared.

Patient and public involvement Patients and/or the public were involved in the design, or conduct, or reporting or dissemination plans of this research. Refer to the Methods section for further details.

Patient consent for publication Not required.

Ethics approval The study involved secondary analysis of data that are available in the public domain. All participants gave informed consent prior to taking part in the survey.

Provenance and peer review Not commissioned; externally peer reviewed.

Data availability statement Data are available in a public, open access repository. statement data are available upon reasonable reasonable request. The 2017-2018 Jordan Population and Family Health Survey (JPFHS) was the seventh of this kind to be conducted in the country, and was implemented by the Department of Statistics (DOS) from early October 2017 to January 2018 (http://dosweb.dos.gov.jo/products/ dhs2017-2018/).

Open access This is an open access article distributed in accordance with the Creative Commons Attribution Non Commercial (CC BY-NC 4.0) license, which permits others to distribute, remix, adapt, build upon this work non-commercially, and license their derivative works on different terms, provided the original work is properly cited, appropriate credit is given, any changes made indicated, and the use is non-commercial. See: http://creativecommons.org/licenses/by-nc/4.0/.
ORCID iDs

Meilian Liu http://orcid.org/0000-0002-7826-4247

Bishwajit Ghose http://orcid.org/0000-0003-4461-3821

Ruoxi Wang http://orcid.org/0000-0002-9695-0582

Da Feng http://orcid.org/0000-0003-4392-760X

\section{REFERENCES}

1 Nazer LH, Tuffaha $\mathrm{H}$. Health care and pharmacy practice in Jordan. Can J Hosp Pharm 2017;70:150-5.

2 Rashad A, Sharaf M. Catastrophic economic consequences of healthcare payments: effects on poverty estimates in Egypt, Jordan, and Palestine. Economies 2015;3:216-34.

3 Wong YS, Allotey P, Reidpath DD. Sustainable development goals, universal health coverage and equity in health systems: the Orang Asli commons approach. Glob Health Epidemiol Genom 2016;1:e12.

4 Acharya M. Universal health coverage as a distinct sustainable development goals target: Dispelling doubts and underlining implications. Front Public Health 2015;3:238.

5 WHO. Achieving universal health coverage, 2019. Available: https:// www.who.int/bulletin/volumes/93/9/14-149070/en/ [Accessed 26 Mar 2019].

6 Azzani M, Roslani AC, Su TT. Determinants of household catastrophic health expenditure: a systematic review. Malays J Med Sci 2019;26:15-43.

7 Njagi P, Arsenijevic J, Groot W. Understanding variations in catastrophic health expenditure, its underlying determinants and impoverishment in Sub-Saharan African countries: a scoping review. Syst Rev 2018;7:136.

8 Xu K, Evans DB, Kadama P, et al. Understanding the impact of eliminating user fees: utilization and catastrophic health expenditures in Uganda. Soc Sci Med 2006;62:866-76.

9 Masiye F, Kaonga O, Kirigia JM. Does user fee removal policy provide financial protection from catastrophic health care payments? Evidence from Zambia. PLoS One 2016;11:e146508.

10 Garcia-Subirats I, Vargas I, Mogollón-Pérez AS, et al. Barriers in access to healthcare in countries with different health systems. A cross-sectional study in municipalities of central Colombia and north-eastern Brazil. Soc Sci Med 2014;106:204-13.

11 Richardson E, Roberts B, Sava V, et al. Health insurance coverage and health care access in Moldova. Health Policy Plan 2012;27:204-12.

12 Kingston LN, Cohen EF, Morley CP. Debate: limitations on universality: the "right to health" and the necessity of legal nationality. BMC Int Health Hum Rights 2010;10:11.

13 Ferguson J. Formalities of poverty: thinking about social assistance in neoliberal South Africa. Afr Stud Rev 2007;50:71-86.

14 Stafford M, Marmot M. Neighbourhood deprivation and health: does it affect us all equally? Int J Epidemiol 2003;32:357-66.

15 Gupta RP-S, de Wit ML, McKeown D. The impact of poverty on the current and future health status of children. Paediatr Child Health 2007;12:667-72.

16 Loignon C, Hudon C, Goulet Émilie, et al. Perceived barriers to healthcare for persons living in poverty in Quebec, Canada: the EQUlhealThY project. Int J Equity Health 2015;14:4.

17 Khullar D, Chokshi DA. Health, income, poverty: where we are; what could help. Health Affairs 2018.

18 Alkhawaldeh A, Holm MB, Qaddumi J, et al. A cross-sectional study to examine factors associated with primary health care service utilization among older adults in the Irbid Governorate of Jordan. Curr Gerontol Geriatr Res 2014;2014:735235

19 Chukwudozie A. Inequalities in health: the role of health insurance in Nigeria. J Public Health Afr 2015;6:512.

20 Wu Y, Zhang L, Liu X, et al. Geographic variation in health insurance benefits in Qianjiang district, China: a cross-sectional study. Int J Equity Health 2018;17:20.

21 Sohn H. Racial and ethnic disparities in health insurance coverage: dynamics of gaining and losing coverage over the life-course. Popul Res Policy Rev 2017;36:181-201.

22 Kirigia JM, Sambo LG, Nganda B, et al. Determinants of health insurance ownership among South African women. BMC Health Serv Res 2005;5:17.

23 Yaya S, Da F, Wang R, et al. Maternal healthcare insurance ownership and service utilisation in Ghana: analysis of Ghana demographic and health survey. PLoS One 2019;14:e0214841.

24 Kimani JK, Ettarh R, Warren C, et al. Determinants of health insurance ownership among women in Kenya: evidence from the 2008-09 Kenya demographic and health survey. Int J Equity Health 2014;13:27. 
25 Bishwajit G, Yaya S. Household food insecurity is independently associated with poor utilization of maternal healthcare services in Bangladesh. FACETS 2017;2:969-83.

26 Sakshaug JW, West BT. Important considerations when analyzing health survey data collected using a complex sample design. Am J Public Health 2014;104:15-16.

27 Jordan Times. THE JORDAN TIMES. '55\% of population, $68 \%$ of Jordanians covered by health insurance', 2016. Available: http:// www.jordantimes.com/news/local/55-population-68-jordanianscovered-health-insurance\%E2\%80\%99 [Accessed 13 Mar 2020].

28 Pandey KR, Yang F, Cagney KA, et al. The impact of marital status on health care utilization among Medicare beneficiaries. Medicine 2019;98:e14871.

29 Annesi JJ. Relations of age with changes in self-efficacy and physical self-concept in preadolescents participating in a physical activity intervention during afterschool care. Percept Mot Skills 2007;105:221-6.

30 Tsang SKM, Hui EKP, Law BCM. Self-efficacy as a positive youth development construct: a conceptual review. Sci World J 2012;2012:452327

31 Salinas JJ, Al Snih S, Markides K, et al. The rural-urban divide: health services utilization among older Mexicans in Mexico. J Rural Health 2010;26:333-41.

32 Yaya S, Bishwajit G, Ekholuenetale M, et al. Urban-rural difference in satisfaction with primary healthcare services in Ghana. BMC Health Serv Res 2017; 17:776.

33 Doménech-Betoret F, Abellán-Roselló L, Gómez-Artiga A. Selfefficacy, satisfaction, and academic achievement: the mediator role of students' expectancy-value beliefs. Front Psychol 2017;8:1193.

34 Allin S, Masseria C, Mossialos E. Measuring socioeconomic differences in use of health care services by wealth versus by income. Am J Public Health 2009;99:1849-55.

35 Jordan Times. Ministry allows citizens to apply for gov't health insurance online, 2016. Available: http://www.jordantimes.com/ news/local/ministry-allows-citizens-apply-gov\%E2\%80\%99t-healthinsurance-online [Accessed 13 Mar 2020].
36 Carroll JK, Moorhead A, Bond R, et al. Who uses mobile phone health Apps and does use matter? a secondary data analytics approach. J Med Internet Res 2017;19:e125.

37 Vangeepuram N, Mayer V, Fei K, et al. Smartphone ownership and perspectives on health apps among a vulnerable population in East Harlem, New York. Mhealth 2018;4:31.

38 Kumar D, Hemmige V, Kallen MA, et al. Mobile phones may not bridge the digital divide: a look at mobile phone literacy in an underserved patient population. Cureus 2019;11:e4104

39 Anderson-Lewis C, Darville G, Mercado RE, et al. mHealth technology use and implications in historically underserved and minority populations in the United States: systematic literature review. JMIR Mhealth Uhealth 2018:6:e128.

40 Jordan Health Insurance - Pacific Prime Internationa, 2020. Available: https://www.pacificprime.com/country/middle-east/ jordan-health-insurance-pacific-prime-internationa/ [Accessed 13 Mar 2020].

41 El Arnaout N, Rutherford S, Zreik T, et al. Assessment of the health needs of Syrian refugees in Lebanon and Syria's neighboring countries. Confl Health 2019;13:31.

42 Rawabdeh AA, Khassawneh AS. Health financing policies in Jordan: the allocation of public expenditures in global context. MSK 2018;22:153-6.

43 Dator W, Abunab H, Dao-Ayen N. Health challenges and access to health care among Syrian refugees in Jordan: a review. East Mediterr Health J 2018;24:680-6.

44 Al-Fahoum AS, Diomidous M, Mechili A. The provision of health services in Jordan to Syrian refugees. Health Sci J 2015;9.

45 El Arab R, Sagbakken M. Healthcare services for Syrian refugees in Jordan: a systematic review. Eur J Public Health 2018;28:107987

46 Jordan Health Insurance. Health access and utilization survey: access to healthcare services among syrian refugees in Jordan - December 2018 - Jordan, 2020. Available: https://reliefweb. int/report/jordan/health-access-and-utilization-survey-accesshealthcare-services-among-syrian-refugees [Accessed 13 Mar 2020]. 